\title{
Minimum Dietary Diversity and Associated Factors Among Pregnant Women Attending Antenatal Care in Government Health Facilities of Soro District, Hadiya Zone, Southern Ethiopia
}

Tegegn Tadesse ( $\nabla$ tegegntadesse24@gmail.com )

Wachamo University

Abera Beyamo

Wachamo University

Yilma Markos

Wachamo University

Dawit Sulamo

Wachamo University

Lire Lema

Wachamo University

Mengistu Handiso

Wachamo University

Lonsako Abute

Wachamo University

Fitsum Endale

Wachamo University

Research Article

Keywords: prevalence, minimum dietary diversity, Ethiopia, pregnant, women

Posted Date: January 3rd, 2022

DOI: https://doi.org/10.21203/rs.3.rs-1043452/v1

License: (c) (i) This work is licensed under a Creative Commons Attribution 4.0 International License.

Read Full License 


\section{Abstract}

Background: Dietary diversity is a good proxy indicator for micronutrient adequacy in pregnant women. Despite some improvements in dietary intake among pregnant mothers, achieving the minimum dietary diversity among them is still a great challenge in Ethiopia. There are no enough studies done on minimum dietary diversity among pregnant women and factors identified were more of local based. Therefore this study determined the prevalence of minimum dietary diversity and its associated factors among pregnant women attending antenatal care in government health facilities of Soro district, Hadiya Zone, Southern Ethiopia.

Methods: This is the facility based study conducted in government health facilities of Soro district, Hadiya Zone from Oct. 2020-Jan 2021. Cross sectional study design was undertaken by using systematic sampling on 422 pregnant women attending antenatal care. Both bivariate and multivariable logistic regression analysis were used to assess the association of independent variables with outcome variable.

Result: From the total of the 422 study subjects, 416 pregnant women attending antenatal care were participated in the study and making the response rate 98.6 percent. The overall prevalence of pregnant mothers who have met the minimum dietary diversity was only $7.9 \%$. Maternal educational status being grade nine above, eating meal more than three times per day and women being currently not married were factors found to be significantly associated with minimum dietary diversity among pregnant mothers attending antenatal care in government health facilities.

Conclusion: The prevalence of the minimum dietary diversity among pregnant women attending ANC in public health facilities of Soro district was very low and far from national and international recommendations to enhance the maternal food diversity. Inter sectoral collaboration is very important to enhance the minimum dietary diversity during pregnancy and should be worked intensively and in an integrated manner.

\section{Introduction}

Maternal nutrition is one of the greatest opportunities to improve the health across generations. WHO says good maternal nutrition as the best start in life [1]. Maternal nutrition is not only critical to reduce mortality and disability, but is the foundation for a child's growth and development. The most critical window of opportunity for impactful intervention is the first 1,000 days of a child's life that includes pregnancy and the first two years of life after birth. Pregnancy is a special period in human life with influence on not only pregnant women, but also on the health and productivity of the next generation. Interventions during this period of time support a broader lifecycle approach to nutrition. Appropriate nutrition is the most critical one to ensure optimum physical and cognitive development [2-4].

If a woman is malnourished during pregnancy, or if her child is malnourished during the first two years of life, the child's physical and mental growth and development may be slowed. Hence how women eat and 
maternal nutritional status during pregnancy is very important for better health of the mother as well as for better and healthy growth and development of the child [4-6].

Dietary diversity is a good proxy indicator for micronutrient adequacy in pregnant women. The fetus is dependent on the range of micronutrients circulating in the mother's blood supply for optimal. It is essential for mothers, caregivers, family members, and communities to have accurate information on how women should eat during pregnancy and breastfeeding $[1,5]$. However, Pregnancy is the life threatening situation though it is a normal physiological event in life stage in Africa. Sub-Saharan Africa is a region known by highest maternal and child mortality in the world. In sub-Saharan Africa 32 million babies are born small for gestational age (SGA) annually representing $27 \%$ of all births in low and middle income countries. Furthermore fetal growth restriction causes more than 800000 deaths each year in the first month of life and follows with substantially increased risk of being stunted among children [7].

The consequence of the maternal malnutrition is not limited on mother but it has also both short and long term implications for offspring. It sets a stage for poor pregnancy outcomes, affecting the survival and quality of the offspring. Studies show that poor quality of diet for women is the main factor for energy and micronutrient deficiencies among pregnant women [7].

Despite some improvement in nutritional status of mothers and children, maternal undernutrition is still a challenge in Ethiopia [4, 8]. Intake of macro and micronutrients were below the recommendation among pregnant women in rural area, Southern Ethiopia. Nearly all (99.0\%) of the pregnant women were deficient in niacin, folate and calcium. More over only quarter of women had succeeded adequate food intake during their pregnancy [9]. Fear of big fetuses, abortion, less blood, lack of strength during birth, miscarriages or stillbirths, and maternal deaths as well as child's colic and poor skin conditions after birth are identified reasons for mothers to be restricted to take healthy foods during pregnancy $[10,11]$. There is no recent study done on dietary diversity and its associated factors among pregnant women at the study area. Therefore this study determined the prevalence of minimum dietary diversity and its associated factors among pregnant women attending antenatal care (ANC) in government health facilities of Soro district, Hadiya Zone, Southern Ethiopia.

\section{Methods}

\section{Study design and setting}

This study was undertaken in government health facilities located in Soro district, Hadiya Zone which is located in $32 \mathrm{~km}$ from Zonal city, Hosanna and 262km from Addis Ababa. The district has thirty two rural kebeles. It hast five health centers serving more than 125000 people [12]. Facility based cross sectional study was employed to assess the prevalence and factors associated with minimum dietary diversity among pregnant women attending antenatal care in public health centers.

\section{Study population}


All pregnant women who have been attending antenatal care in government health facilities at Soro district were source population of this study. The study population was those pregnant women who were randomly selected for the study within in the selected health facilities. Pregnant women who were severely ill, unable to hear and talk were excluded from the study.

\section{Sample size determination and sampling technique}

By considering an anticipated proportion of adequate dietary diversity among pregnant women $50 \%, 5 \%$ type I error, margin of error $5 \%$ and $10 \%$ contingency for the non-response the final sample size was 422 . Systematic sampling was applied to select those study subjects by preparing the K-value and by randomly selecting the first number to commence the study at each health facility.

\section{Operational definition}

Minimum dietary diversity: The proportion of the pregnant women 15-49 years of age who have consumed at least five out of ten defined food groups in the previous day or night [13].

\section{Data collection processes and tools}

Quantitative data were collected through face to face interview by using standard pretested questionnaires which were extracted from recognized sources. Data collectors were trained for two days on purpose of the study, how to collect data and ethical considerations. Questionnaire was prepared in English and translated into Amharic and then translated back to English language by fluent speakers of both languages. Data collection was undertaken from Oct. 2020-Jan 2021 by hiring five data collectors and three supervisors who have experience on data collection.

\section{Data processing, analysis and presentation}

After field work data were checked for completeness and consistence before data entry and cleaning. Then data were entered and analyzed by SPSS for windows version 20 (SPSS Inc. version 20, Chicago, Illinois). Descriptive summary was presented by using frequencies, proportions, means and tables. Both bivariate and multivariable logistic regression analysis were used to assess the association of independent variables with outcome variable and to control the possible confounding factors. Those independent variables with $p$-value less than or equal to 0.25 were candidates for multivariable logistic regression and finally variables with p-value less than 0.05 in multivariable logistic regression were selected as significantly associated with the outcome variable.

\section{Result}

\section{Socio demographic characteristics of the study participants}

From the total of the 422 study subjects, 416 pregnant women attending antenatal care were participated in the study and making the response rate 98.6 percent. The mean age was 27.34 year $(S D \pm 4.34)$. More 
than two third $323(77.6 \%)$ of the respondents were protestants in their religion and most were married $391(94.0 \%)$. According to the ethnicity, majority 366(88.0\%) were the Hadiya ethnic groups. Nearly half of the pregnant women had attended 1-8 class in their education and most of them were housewives in their occupation (Table 1). 
Table 1

Socio demographic characteristics of the pregnant mothers attending ANC in rural health facilities of Soro district, Hadiya Zone, Southern Ethiopia, Oct.

2020-Jan $2021(n=416)$

\begin{tabular}{|c|c|c|c|}
\hline Variable & & number & percent \\
\hline \multirow{3}{*}{$\begin{array}{l}\text { Current marital } \\
\text { status }\end{array}$} & Single & 22 & 5.3 \\
\hline & Married & 391 & 94.0 \\
\hline & widowed & 3 & 0.7 \\
\hline \multirow[t]{3}{*}{ age } & 15-25years & 168 & 40.4 \\
\hline & $26-30$ years & 170 & 40.9 \\
\hline & $>30$ year & 78 & 18.8 \\
\hline \multirow{4}{*}{$\begin{array}{l}\text { Mother's } \\
\text { religion }\end{array}$} & Protestant & 323 & 77.6 \\
\hline & Orthodox & 62 & 14.9 \\
\hline & Catholic & 29 & 7.0 \\
\hline & Muslim & 2 & 0.5 \\
\hline \multirow[t]{5}{*}{ Ethnicity } & Hadiya & 366 & 88.0 \\
\hline & Kambata & 28 & 6.7 \\
\hline & Tambaro & 16 & 3.8 \\
\hline & Amhara & 4 & 1.0 \\
\hline & Other* & 2 & 0.5 \\
\hline \multirow[t]{4}{*}{ Occupation } & Housewife & 341 & 82.0 \\
\hline & Gov't worker & 13 & 3.1 \\
\hline & Merchant & 49 & 11.8 \\
\hline & Other $^{1}$ & 13 & 3.1 \\
\hline \multirow{4}{*}{$\begin{array}{l}\text { Mother's } \\
\text { education }\end{array}$} & Unable to read and write & 68 & 16.3 \\
\hline & Able to read and write & 100 & 24.0 \\
\hline & 1-8 grade & 191 & 45.9 \\
\hline & 9 and above grades & 57 & 13.7 \\
\hline \multirow[t]{2}{*}{ Monthly income } & $<500$ ETB & 78 & 18.8 \\
\hline & 500-1000ЕTB & 62 & 14.9 \\
\hline${ }^{*}$ Gurage, Dawuro & & 85 & 20.4 \\
\hline
\end{tabular}




\begin{tabular}{|c|c|c|c|}
\hline \multicolumn{2}{|l|}{ Variable } & nưmber & p.5.9. \\
\hline & $>1000$ ETB & & \\
\hline & I don't know & & \\
\hline \multirow[t]{4}{*}{ Household Wealth index } & poorest & 109 & 26.2 \\
\hline & poor & 58 & 13.9 \\
\hline & Middle & 106 & 25.5 \\
\hline & rich & 143 & 34.4 \\
\hline
\end{tabular}

\section{Obstetric and maternal health characteristics of the pregnant women}

Majority of the households $265(63.7 \%)$ with pregnant women had more than or equal to five household members. One hundred seventy nine $(43.0 \%)$ of the pregnant women had a gravidity of either four up to five likewise majority $179(43.0 \%)$ had a live birth of three up to four children. Nearly half of the respondents $198(47.6 \%)$ were in the second trimester of the pregnancy during the study. According to the health status, most of the pregnant women $356(85.6 \%)$ had no any illness within the last one month as they had reported orally. Typhoid fever was reported by more than one third of those experienced illness within one month prior to the date of the data collection (Table2). 
Table 2

Obstetric and maternal health characteristics of among pregnant women attending ANC in health facilities, rural Soro district, Hadiya Zone, Southern Ethiopia Oct 2020-Jan $2021(n=416)$

\begin{tabular}{|c|c|c|c|}
\hline Variable & & number & percent \\
\hline \multirow[t]{2}{*}{ Number of household members } & 4 and below & 151 & 36.3 \\
\hline & 5 and above & 265 & 63.7 \\
\hline \multirow[t]{3}{*}{ Number of pregnancy } & 1 up to 3 & 140 & 33.7 \\
\hline & 4 up to 5 & 179 & 43.0 \\
\hline & 6 and above & 97 & 23.3 \\
\hline \multirow[t]{3}{*}{ Number of live birth } & $\leq 2$ children & 141 & 33.9 \\
\hline & 3-4 children & 179 & 43.0 \\
\hline & 5 and above & 96 & 23.1 \\
\hline \multirow[t]{3}{*}{ Trimester } & first & 93 & 22.4 \\
\hline & second & 198 & 47.6 \\
\hline & third & 125 & 30.0 \\
\hline \multirow[t]{2}{*}{ Illness in last 30 days } & yes & 60 & 14.4 \\
\hline & no & 356 & 85.6 \\
\hline \multirow[t]{4}{*}{ Type of illness } & anemia & 9 & 15.0 \\
\hline & malaria & 16 & 26.7 \\
\hline & Typhoid & 22 & 36.7 \\
\hline & other & 13 & 21.7 \\
\hline
\end{tabular}

\section{Dietary diversity and related characteristics among pregnant women}

The overall prevalence of pregnant mothers who have met the minimum dietary diversity was only $7.9 \%$.

The starchy staple constitutes the food group that was eaten by almost all of the respondents 414(99.5\%) within 24 hours prior to undertake the study. Inversely, nuts and seeds are the least food items consumed by respondents 5(1.2\%). Majority of pregnant women 356(85.6) attending ANC reported that they had got three meals and less one day before the interview was taken. Besides, most of the mothers $358(86.1 \%)$ did not get additional meal in addition to their daily dish shared with their family members. Depending on food avoidance during pregnancy, 82(19.7\%) of the study participants have reported as restricted from eating a certain food types during their pregnancy mainly due to the cultural taboos (Table3). 
Table 3

Dietary diversity and related characteristics among pregnant women attending ANC in health facilities, rural Soro district, Hadiya Zone, Southern Ethiopia Oct 2020-Jan $2021 \quad(n=416)$

\begin{tabular}{|c|c|c|c|c|}
\hline \multicolumn{3}{|l|}{ Variable } & \multirow{2}{*}{$\begin{array}{l}\text { number } \\
33 \\
383\end{array}$} & \multirow{2}{*}{$\begin{array}{l}\text { percent } \\
7.9 \\
92.1\end{array}$} \\
\hline \multicolumn{2}{|c|}{ Dietary diversity } & adequate & & \\
\hline \multirow{22}{*}{$\begin{array}{l}\text { Food } \\
\text { groups } \\
\text { consumed }\end{array}$} & \multirow{3}{*}{ Starchy staples } & & \multirow{3}{*}{414} & \multirow{3}{*}{99.5} \\
\hline & & yes & & \\
\hline & & no & & \\
\hline & \multirow[t]{2}{*}{ Dark green leafy vegetables } & yes & \multirow[t]{2}{*}{2} & \multirow[t]{2}{*}{0.5} \\
\hline & & no & & \\
\hline & \multirow[t]{2}{*}{$\begin{array}{l}\text { Other vitamin A rich fruits and } \\
\text { vegetables }\end{array}$} & yes & \multirow[t]{2}{*}{54} & \multirow[t]{2}{*}{13.0} \\
\hline & & no & & \\
\hline & \multirow[t]{2}{*}{ Other fruits and vegetables } & yes & \multirow[t]{3}{*}{362} & \multirow[t]{3}{*}{87.0} \\
\hline & & no & & \\
\hline & \multirow[t]{2}{*}{ Milk and milk products } & Yes & & \\
\hline & & no & \multirow[t]{3}{*}{59} & \multirow[t]{3}{*}{14.2} \\
\hline & \multirow[t]{2}{*}{ Legumes } & yes & & \\
\hline & & No & & \\
\hline & \multirow[t]{2}{*}{ Nuts and seeds } & yes & \multirow{2}{*}{357} & \multirow[t]{2}{*}{85.8} \\
\hline & & no & & \\
\hline & \multirow[t]{2}{*}{ Meat and fish } & yes & \multirow{2}{*}{374} & \multirow{2}{*}{89.9} \\
\hline & & no & & \\
\hline & \multirow[t]{4}{*}{ Egg } & Yes & \multirow{2}{*}{42} & \multirow{2}{*}{10.1} \\
\hline & & no & & \\
\hline & & & 173 & 41.6 \\
\hline & & & 243 & 58.4 \\
\hline & & & 193 & 46.4 \\
\hline
\end{tabular}


Got additional meal
Meal frequency

Per day

3 and less

$\geq 4$ meals

yes

no

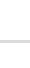

Number of additional meal

Food avoided

during pregnancy

yes

356

85.6

60

58

13.9

86.1

358

58

13.9

10

2.4

82

19.7

no

334

80.3

Personal dislike

27

34.2

Cultural taboo

Will make baby big and

40

50.6 labor difficult

Other 


\section{Factors associated with adequate minimum dietary diversity among pregnant women}

On bivariate logistic regression getting additional meal COR $(95 \% \mathrm{Cl}): 8.9(4.2,18.9)$, having radio COR $(95 \% \mathrm{Cl}): 2.8(1.3,6.2)$, receiving extra one meal COR $(95 \% \mathrm{Cl}): 10(4.7,21.4)$, meal frequency being more than three times per day COR $(95 \% \mathrm{Cl}): 8.4(3.9,17.8)$, maternal education being grade 9 and above COR (95\% Cl): 16.5(3.6,74.7), having five and above household members COR $(95 \% \mathrm{Cl}): 2.6(1.3,5.3)$ and marital status COR $(95 \% \mathrm{Cl}): 0.31(0.11,0.88)$ were factors associated with minimum dietary diversity among pregnant women. However, during multivariable logistic regression maternal educational status being grade nine above, eating meal more than three times per day and women being currently not married were factors found to be significantly associated with minimum dietary diversity among pregnant mothers attending antenatal care in government health facilities.

Pregnant women who have attended grade 9 and above in their education had 8.5 times more odds of getting minimum dietary diversity than those who were unable to read and write. Those who consumed food four and more times were 6.1 times more likely to practice minimum dietary diversity than their counterparts who received three and less times in the previous day. Mothers were in the marriage at the time had 8 percent less odds of having minimum dietary diversity than those who were not in the marriage (Table 4). 
Table 4

Factors associated with adequate minimum dietary diversity among pregnant women ANC in health facilities, rural Soro district, Hadiya Zone, Southern Ethiopia Oct 2020-Jan 2021 ( $n=416$ )

\begin{tabular}{|c|c|c|c|c|c|}
\hline \multirow[t]{2}{*}{ variable } & & \multicolumn{2}{|c|}{$\begin{array}{l}\text { Minimum dietary } \\
\text { diversity }\end{array}$} & \multirow[t]{2}{*}{$\operatorname{COR}(95 \% \mathrm{Cl})$} & \multirow[t]{2}{*}{$\mathrm{AOR}(95 \% \mathrm{Cl})$} \\
\hline & & Yes (\%) & No (\%) & & \\
\hline \multirow[t]{2}{*}{ Additional meal } & yes & 17(29.3) & $41(70.7)$ & $8.9(4.2,18.9)$ & $0.9(0.1,13.3)$ \\
\hline & no & $16(4.5)$ & $342(95.5)$ & 1 & 1 \\
\hline \multirow[t]{2}{*}{ Radio } & yes & $24(11.4)$ & 186(88.6) & $2.8(1.3,6.2)$ & $2.5(0.9,6.9)$ \\
\hline & no & $9(4.4)$ & 197(95.6) & 1 & 1 \\
\hline \multirow{3}{*}{$\begin{array}{l}\text { Number of extra } \\
\text { meal }\end{array}$} & one & 18(31.0) & $40(69.0)$ & $10(4.7,21.4)$ & $4.5(0.4,50.4)$ \\
\hline & two & - & 10(100) & 1 & 1 \\
\hline & no & $15(4.3)$ & $333(95.7)$ & & \\
\hline \multirow{5}{*}{$\begin{array}{l}\text { Mother's } \\
\text { education }\end{array}$} & \multirow{2}{*}{$\begin{array}{l}\text { Unable to read } \\
\text { and write }\end{array}$} & \multirow{2}{*}{$\begin{array}{l}2(2.9) \\
2(2.0)\end{array}$} & $66(97.1)$ & \multirow[t]{3}{*}{1} & \multirow[t]{3}{*}{1} \\
\hline & & & & & \\
\hline & $\begin{array}{l}\text { ADle to read and } \\
\text { write }\end{array}$ & \multirow{3}{*}{$\begin{array}{l}10(5.2) \\
19(33.3)\end{array}$} & $181(94.8)$ & & \\
\hline & 1-8 grade & & $38(66.7)$ & \multirow[t]{2}{*}{$16.5(3 \cdot 6,74.7)$} & \multirow[t]{2}{*}{$8.5(1.4,52.0)$ * } \\
\hline & 9 and above & & & & \\
\hline \multirow[t]{2}{*}{ Marital status } & Currently married & $28(7.2)$ & $363(92.8)$ & $0.31(0.11,0.88)$ & $0.08(0.02,0.37)^{\star \star}$ \\
\hline & others & $5(20.0)$ & $20(80.0)$ & 1 & 1 \\
\hline \multirow[t]{2}{*}{ Meal frequency } & 3 and less times & $16(4.5)$ & $340(95.5)$ & 1 & 1 \\
\hline & $\begin{array}{l}4 \text { and above } \\
\text { times }\end{array}$ & 17(28.3) & 43(71.7) & $8.4(3.9,17.8)$ & $6.1(1.6,22.9)$ ** \\
\hline \multirow{2}{*}{$\begin{array}{l}\text { Household } \\
\text { size }\end{array}$} & 4 and below & 19(12.6) & 132(87.4) & $2.6(1.3,5.3)$ & $1.6(0.6,4.2)$ \\
\hline & 5 and above & $14(5.3)$ & 251(94.7) & 1 & 1 \\
\hline
\end{tabular}

\section{Discussion}

This study was conducted to determine prevalence and factors associated with minimum dietary diversity among pregnant women attending ant natal care (ANC) in public health facilities. The overall proportion of the pregnant women who met minimum dietary diversity was $7.9 \%$ with $95 \% \mathrm{Cl}:(5.2$, $10.6 \%)$. The finding of this study was lower than studies conducted in Ethiopia and other countries. It is lower than the findings in studies undertaken in Bale Zone (43.8\%), South East Ethiopia, Gojam (45\%), 
Northern Ethiopia, Shashemane (25.4\%), Ethiopia and Ghana (46.1\%)[11, 14-16]. This might be due to the fact that the season when the study undertaken affected the study finding. Even though it is the harvesting season around the study area, most food products are starchy sources mainly barley, wheat, maize and teff. It might also be due to the new FAO 2016 guideline where the study tool was adapted, that recommends considering a pregnant woman achieved minimum dietary diversity if a pregnant woman consumes at least five out of ten food groups in the previous 24 hours.

Starchy staples were the most common food group eaten by respondents (99.5\%). This might be due to more production of starchy foods in the study area and low purchasing power to access fruits and animal products from the market. It might also be due to lack of awareness on diversifying diets with low cost and effort among pregnant women and within the community where the women from. The finding is in line with the study done in Eastern Ethiopia and Kenya [17]. However, the study conducted in Gojam, Northern Ethiopia [15] indicated that legumes, nuts, and seeds (85.5\%) were the most commonly consumed food groups.

In this study maternal education was associated with achieving the minimum dietary diversity among pregnant mothers attending ante natal care. Women who have attended grade 9 and above in their education had 8.5 times more odds of getting minimum dietary diversity than those who were unable to read and write. The finding is similar with the study done in Shashemane, Ethiopia where pregnant women who had tertiary and secondary education had three times and two times more likely to achieve the adequate dietary diversity, respectively, as compared to those who had no formal education. It also agrees with studies conducted in Jille Tumuga, North eastern Ethiopia, East Gojam, North West Ethiopia and Kenya $[11,15,17,18]$. This indicates as the education status of women increases the likelihood getting diverse diet increases. This might be that fact that as the more mothers educated the chance to get the nutrition information either by reading, learning or watching from different sources might be extended.

The frequency of the diet in the previous day prior to study is found to be a factor associated with minimum dietary diversity among pregnant women. In this study those who consumed food four and more times were 6.1 times more likely to practice minimum dietary diversity than their counterparts who received three and less times in the previous day. This might be the fact that as the frequency of the diet increases it provides the pregnant women an opportunity to get a diet from different food groups. It is a common habit in the study area that the pattern of eating foods depends on the specific time of the day. It is culture to practice cereal and grain sources with coffee in the morning and kocho (product of false banana) or enjera( bread made of teff or wheat) with cabbage or wot (stew made of bean or pea) in the mid day or night. If pregnant women get snack, it may add an access to get additional meal from different food groups. The finding is consistent with the studies done in Alemata Hosiptal, Northern Ethiopia and Finote selam town, North West Ethiopia $[19,20]$ where pregnant women those who got three and more meals per day had more odds of meeting minimum dietary diversity than their counterparts. 
This study reports the finding which is inconsistent with other studies that marital status was associated with minimum dietary diversity. Mothers were currently married had 8 percent less odds of having minimum dietary diversity than those who were not in the marriage. This might be the fact that culturally and religiously common to women should give priority for their husbands and gusts in the house and there is a belief that tasty and delicious foods should given for them to show the respect from wives. Sample size may also affect the finding as most of the respondents were currently married and incomparable in proportion with those who were single, widowed or separated during the study.

This study has its own limitations. The nature of the study being a cross sectional study is difficult to ascertain the causation of the selected factors with minimum dietary diversity among pregnant women. Recall bias and social desirability might affect the study as the study was based on twenty four hour recall and there might be reporting socially acceptable and common diet during the interview. Seasonality may also affect the study as the access for different foods depends on harvesting season in the study area. Factors related with husbands and household food security were not studied and need to be considered in the future studies.

\section{Conclusion And Recommendation}

The prevalence of the minimum dietary diversity among pregnant women attending ANC in public health facilities of Soro district was very low and far from national and international recommendations to enhance the maternal food diversity. The maternal education being grade 9 and above, meal frequency being four and above and being currently unmarried were the factors independently associated with meeting minimum dietary diversity among pregnant women.

Inter sectoral collaboration is very important to enhance and extend the formal and nutrition education for females and should be worked intensively and in integrated manner. Agricultural sector should work in nutrition sensitive food production which increases the access for pregnant women to receive locally prepared nutritious foods and to consume at least four times within one day. Health workers those who work in ANC clinic should focus on maternal nutrition counseling and advocacy that ensures pregnant mothers to get their meal from different food groups by using nutrition education and communication tools. Household and community based awareness creation activities should be done on improving the dietary diversity of the mothers currently in marriage.

\section{Declarations}

\section{Ethical approval and consent to participate}

Ethical clearance was obtained from the Wachemo University, college of medicine and health sciences ethical committee. The letter of cooperation was written for Sorro District health office in order to proceed the study. The study was conducted based on voluntary participation by study subjects after explaining the purpose of study. Informed consent was obtained from each participant before starting the interview 
without any obligation or persuading. Anyone had right to withdraw from interview at any time without any harm. No name of participant has been written and code was used instead and confidentiality of data was assured for participants. Privacy and confidentiality of personal information of research subjects have been ensured during the study. The overall method was preformed according to the world medical association (WMA) regulations and principles on research involving human participants.

\section{Acknowledgment}

We would like to thank Wachemo University, data collectors, supervisors, respondents and all individuals involved for their contribution.

\section{Availability of data and material}

The datasets are available from the corresponding author on reasonable request.

\section{Authors' contribution}

Conception and study design TT, LA and DS, Data collection TT, LL, AB and MH Data analysis and interpretation TT, FE, YM and MH, Manuscript drafting TT, YM, AB, MH Manuscript revision FE, LL, DS and LA. All authors approved final version of the manuscript.

\section{Financial disclosure}

This study was supported by Wachemo University.

\section{Competing interest}

The authors declare that they have no competing interests.

\section{Consent for publication}

Not applicable.

\section{References}

1. WHO. Good maternal nutrition: the best start in life. Copenhagen, Denmark, 2016

2. Alive and thrive. Integrating proven maternal nutrition interventions into antenatal care programs: how we can optimize strengths and avoid missed opportunities in India. January 2018

3. Irene Cetin, Arianna Laoreti. The importance of maternal nutrition for health. Journal of Pediatric and Neonatal Individualized Medicine. 4:2, 2015

4. Lancet. Maternal and Child Nutrition: Executive Summary. 2013

5. IYCN Project. Mobilizing communities for improved nutrition. July 2011 
6. Zhang, et al. A Prevalence Analysis to Assess the Relationship between Maternal and Children's Nutritional Status in North-Western Rural China . Clinics Mother Child Health 2016, 13:2

7. Anna Lartey. Maternal and child nutrition in Sub-Saharan Africa: Challenges and interventions. Proceedings of the Nutrition Society. (2008), 67, 105-108 DOI: 10.1017/S0029665108006083

8. Federal Ministry of Health. National Strategy for Newborn and Child Survival in Ethiopia, 2015/16 2029/20. Addis Ababa, Ethiopia, June 2015

9. Asayehu et al. Dietary behaviour, food and nutrient intake of women do not change during pregnancy in Southern Ethiopia. Maternal \& Child Nutrition(2017), 13

10. Riang'a et al. Food beliefs and practices among the Kalenjin pregnant women in rural Uasin Gishu County, Kenya. Journal of Ethnobiology and Ethnomedicine (2017) 13:29

11. Nejimu Biza Zepro. Food taboos and misconceptions among pregnant women of Shashemene district, Ethiopia, 2012. Science Journal of Public Health. Vol. 3, No. 3, 2015, pp. 410-416. doi: 10.11648/j.sjph.20150303.27

12. Soro district health office report. 2020

13. FAO and FHI 360. Minimum Dietary Diversity for Women: A Guide for measurement. Rome: FAO, 2016.

14. Hailu S and Woldemichael B. Dietary diversity and associated factors among pregnant women attending antenatal care at public health facilities in Bale Zone, Southeast Ethiopia. Nutrition and Dietary Supplements. 2019:11 1 - 8

15. Yeneabet $T$ et al. Maternal dietary diversity and micronutrient adequacy during pregnancy and related factors in East Gojjam Zone, Northwest Ethiopia, 2016. BMC Pregnancy child birth. 2019; 19: 173.

16. Mahama Saaka et al. Dietary diversity is not associated with hematological Status of Pregnant Women Resident in Rural Areas of Northern Ghana. Journal of Nutrition and Metabolism.2017

17. Kiboi W et al. Determinants of dietary diversity among pregnant women in Laikipia County, Kenya: a cross-sectional study. BMC Nutrition. 2017, 12(3)

18. Aliwo $S$ et al. Dietary diversity practice and associated factors among pregnant women in North East Ethiopia. BMC. 2019, 12(123)

19. Mekuria $\mathrm{G}$ et al. Household dietary diversity and associated factors among residents of Finote Selam town, North West Ethiopia: a cross sectional study. BMC Nutrition. (2017) 3:28. DOI 10.1186/s40795017-0148-0

20. Kemal Jemal and Mukemil Awol. Minimum dietary diversity score and associated factors among pregnant women at Alamata General Hospital, Raya Azebo Zone, Tigray Region, Ethiopia. Hindawi Journal of Nutrition and Metabolism. 2019 https://doi.org/10.1155/2019/8314359 